\title{
Removal Of Copper From Waste Water Using Low Cost Adsorbent
}

\author{
Jubraj Khamari* Sanjeet Kumar Tiwari** and Anjali Singh*** \\ * Deptt. Of School Of Education, MATS University, Arang, Raipur, (C.G) - INDIA \\ ** Deptt. Of School Of Education, MATS University, Arang, Raipur, (C.G) - INDIA \\ *** Deptt. Of Applied Sciences, Singhania University,Jhunjhunu, Rajasthan- INDIA
}

\begin{abstract}
The sorption of copper (II) on chitosan has been found to be dependent on contact time, concentration, temperature, and $\mathrm{pH}$ of the solution. The process of removal follows first order kinetics and absorption of heat.
\end{abstract}

Keywords: chitosan, bioabsorbent, copper (II), heavy metal adsorption, Chitin.

\section{Introduction}

The general methods of treating wastewater having cadmium follow precipitation and ion exchange. Recently, much interest has been exhibited in the use of sorption technique for the removal of cadmium from wastewater using chitosan. The present investigation aims at using chitosan, a low cost and highly effective sorbent for the removal of cadmium from waste water. Chitosan is a biopolymer, which is extracted from crustacean shells or from fungal biomass. The structure of chitosan is presented schematically in Figure 1.

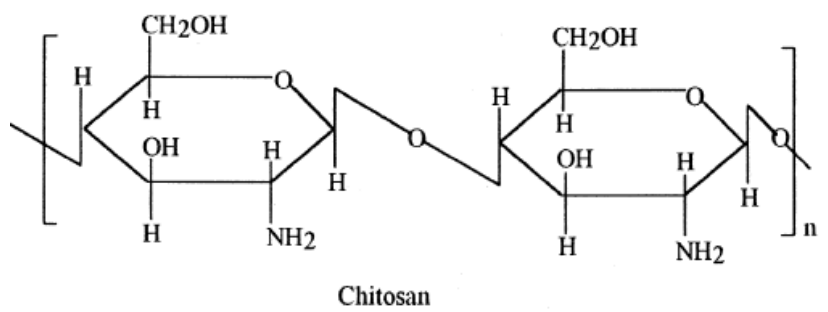

Figure 1 Structure of chitosan

\section{Experimental Procedure}

Chitosan was obtained from India sea foods, cochi (India)

Batch sorption experiments were carried out in temperature controlled shaking machine by agitating $25 \mathrm{ml}$ aqueous solutions of sorbates with $1.0 \mathrm{~g}$ sorbent in different glass bottles at different conditions of concentrations, temperatures and $\mathrm{pH}$. The $\mathrm{pH}$ of different solutions were adjusted with $0.05 \mathrm{M}$ $\mathrm{NaOH}$ or $\mathrm{HCl}$ by $\mathrm{pH}$ meter, systronic 335. The speed of agitation was maintained at $1000 \mathrm{rpm}$ to ensure equal mixing. The progress of sorption was noted after each $20 \mathrm{~min}$. till saturation. At the end of predetermined time interval each $20 \mathrm{~min}$, the sorbate and sorbent were separated by centrifugation at 16,000 rpm and the supernatant liquid analyzed by atomic absorption spectrophotometer. 


\section{Result And Discussion:}

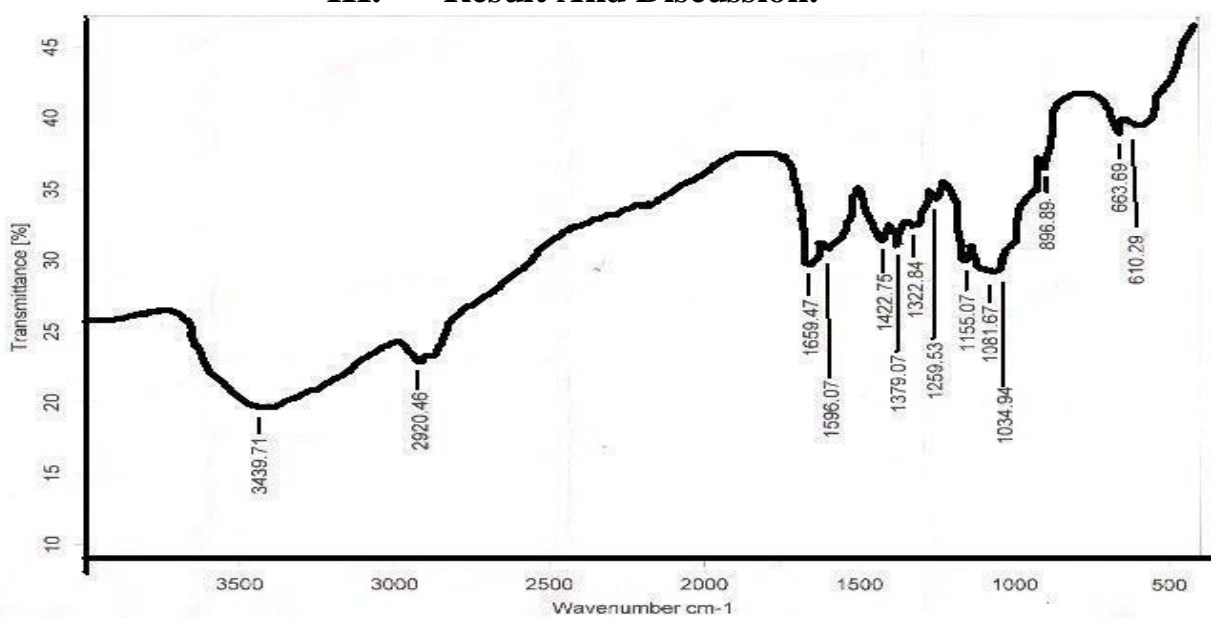

Fig 2: IR spectra of sorption of $\mathrm{Cu}(\mathrm{II})$ on chitosan

\section{Effect Of Contact Time And Concentration}

The removal of cd (II) by sorption on chitosan from aqueous solution increase with time (fig. 2) till equilibrium is attained in $140 \mathrm{~min}$. The fig. shows that time of saturation is independent of concentration. It is further noted that the amount of cd (II) sorbed increases from $1.926 \mathrm{mg} . \mathrm{g}-1$ to $3.814 \mathrm{mg} . \mathrm{g}-1$ by increasing $\mathrm{Cu}$ (II) concentration from $100 \mathrm{mg} / \mathrm{l}$ to $250 \mathrm{mg} / \mathrm{l}$. the time-amount sorbed curve is single, smooth and continuous indicating monolayer coverage ofCu (II) on the outer surface of chitosan.

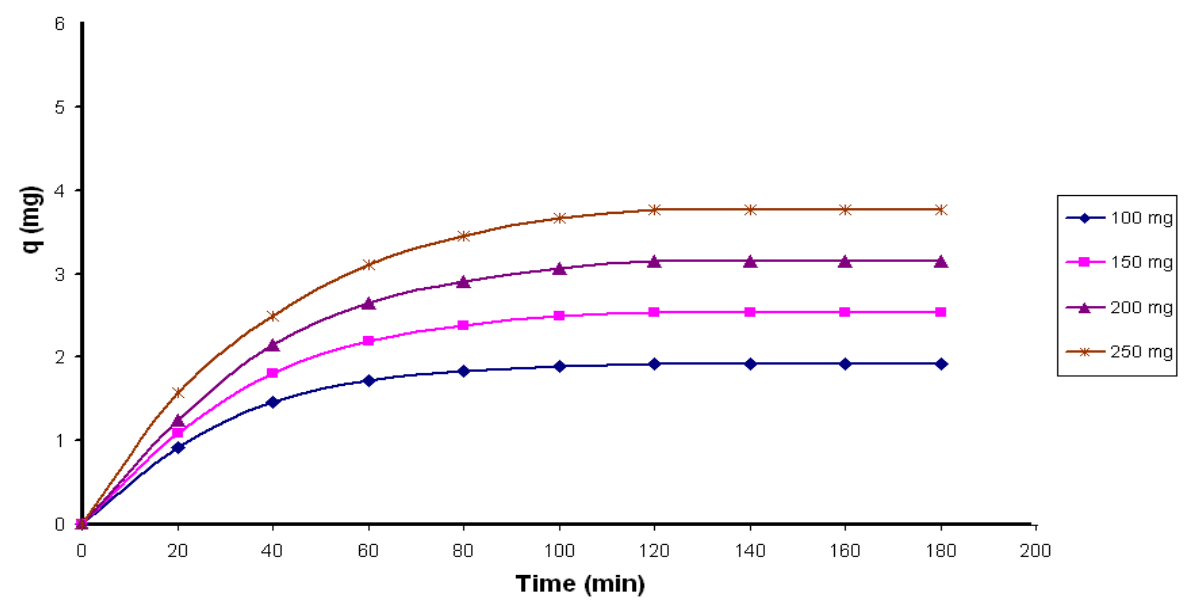

Fig 3 : effect of concentration for the sorption of copper (II) on chitosan; $\bullet 100 \mathrm{mg} / \mathrm{L},=150 \mathrm{mg} / \mathrm{L}, \quad 200 \mathrm{mg} / \mathrm{L}, * 250 \mathrm{mg} / \mathrm{L}$

\section{Sorption Kinetics}

The kinetics of sorption of $\mathrm{Cu}$ (II) on chitosan was studied using Lagergren equation (yadav et. al. 1987)

$$
\log \left(\mathrm{q}_{\mathrm{e}}-\mathrm{q}\right)=\log \mathrm{q}_{\mathrm{e}}-\mathrm{kt} / 2.3
$$

Where $\mathrm{q}_{\mathrm{e}}$ and $\mathrm{q}$ are the amount sorbed (mg.g $\mathrm{g}^{-1}$ ) of $\mathrm{Cu}$ (II) at equilibrium and at time ' $\mathrm{t}$ ' respectively and $\mathrm{k}$ is sorption constant. The straight lines obtained from the plots of $\log \left(\mathrm{q}_{\mathrm{e}}-\mathrm{q}\right)$ against ${ }^{\prime} \mathrm{t}$ ' (fig. 4) and different concentrations indicate that the sorption process follows first order kinetics.

\section{Effect of temperature}

The amount of $\mathrm{Cu}$ (II) sorbed on chitosan increases from $1.927 \mathrm{mg} . \mathrm{g}-1$ to $2.228 \mathrm{mg} . \mathrm{g}-1$ by increasing temperature from $30^{\circ} \mathrm{c}$ to $40^{\circ} \mathrm{c}$ indicating the process to be endothermic (fig. 5). 


\section{Langmuir isotherm}

The equilibrium data at the different temperatures follow Langmuir equation.

$$
\mathrm{C}_{\mathrm{e}} / \mathrm{q}_{\mathrm{e}}=1 / \varphi \cdot \mathrm{b}+\mathrm{C}_{\mathrm{e}} / \varphi
$$

Where Ce mg... $\mathrm{L}^{-1}$ is equilibrium concentration of $c d$ (II) and $\varphi$ and $b$ are Langmuir constants related to sorption capacity and sorption energy respectively. The value of $\varphi$ and $b$ (table 4 ) were determined from the slope and intercept of linear plots Fig. 6 . The sorption capacity also increases with o temperature suggesting that the active centers available for sorption have increased with temperature.

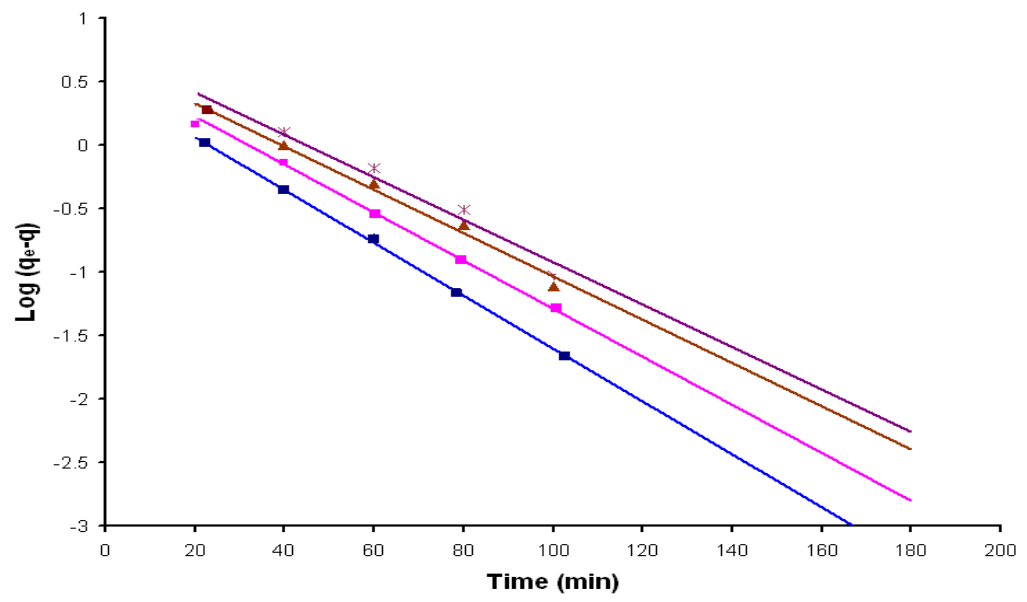

Fig 4: Langergren plot for the sorption of $\mathrm{Cu}$ (II) on chitosan; $\bullet 100 \mathrm{mg} / \mathrm{L},=150 \mathrm{mg} / \mathrm{L}, \quad 200 \mathrm{mg} / \mathrm{L}, * 250 \mathrm{mg} / \mathrm{L}, \mathrm{pH} 5$, temp $30^{\circ} \mathrm{c}$

The change in free energy $\left(\Delta \mathrm{G}^{\circ}\right)$, enthalpy $\left(\Delta \mathrm{H}^{\circ}\right)$, and entropy $\left(\Delta \mathrm{S}^{\circ}\right)$ of sorption have been calculated using following equations.

$$
\begin{aligned}
& \Delta \mathrm{G}^{\circ}=-\mathrm{RT} \ln \mathrm{K} \ldots \ldots \ldots \ldots \ldots \ldots \ldots \ldots \ldots \\
& \Delta \mathrm{H}^{\circ}=\mathrm{RT}_{1} \mathrm{~T}_{2}\left(\mathrm{~T}_{1}-\mathrm{T}_{2}\right) \ln \mathrm{k}_{2} / \mathrm{k}_{1} \\
& \Delta \mathrm{S}^{\circ}=\Delta \mathrm{H}^{\circ}-\Delta \mathrm{G}^{\circ} / \mathrm{T}_{1} \ldots \ldots \ldots \ldots . .
\end{aligned}
$$

Where $K_{1}$ and $K_{2}$ are equilibrium constants at temperature $T_{1}$ and $T_{2}$ respectively.

The negative values of $\Delta \mathrm{G}^{\mathrm{o}}$ (Table 2) indicate the spontaneous nature of the sorption process. The positive values of $\Delta \mathrm{H}^{\circ}$ at different temperature support the endothermic nature of the process.

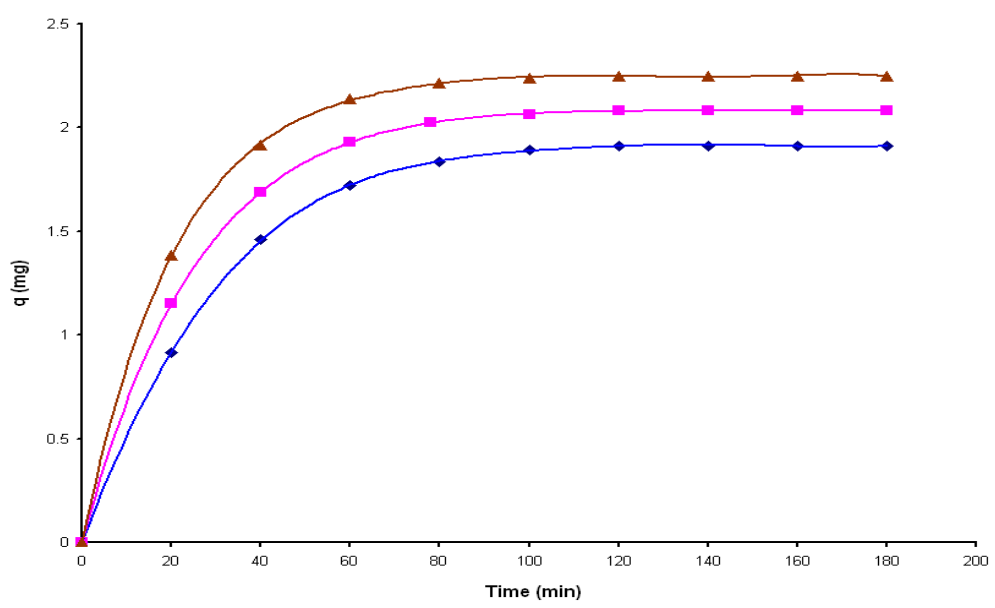

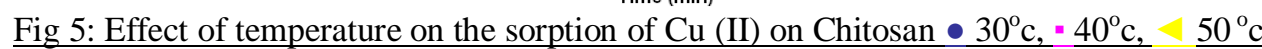




\begin{tabular}{|l|l|l|l|}
\hline Temperature $\left({ }^{\circ} \mathrm{C}\right)$ & $\varnothing$ mg.g-1 & $\mathrm{p}^{\mathrm{H}}$ & $\emptyset$ mg.g-1 \\
\hline 30 & 0.4351 & 2 & 0.4312 \\
\hline 40 & 0.4783 & 4 & 0.4315 \\
\hline 50 & 0.5001 & 6.5 & 0.4568 \\
\hline
\end{tabular}

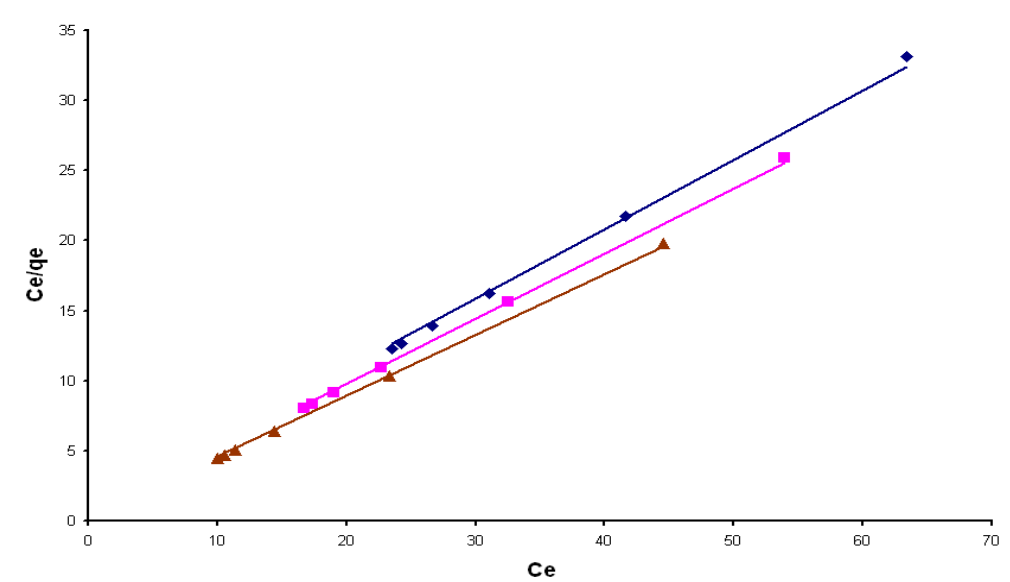

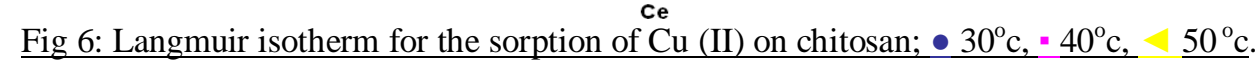

\section{Effect of pH}

The amount of $\mathrm{Cu}$ (II) sorbed on chitosan increases from 1.989mg.g-1 (78.6 \%) to 2.349 mg.g-1 ( $94.2 \%$ ) by increasing $\mathrm{pH}$ of the solution from 2.0 to to 6.5 (Fig.5). The Sorption capacity $\Phi$, also increase with the increase of $\mathrm{pH}$.

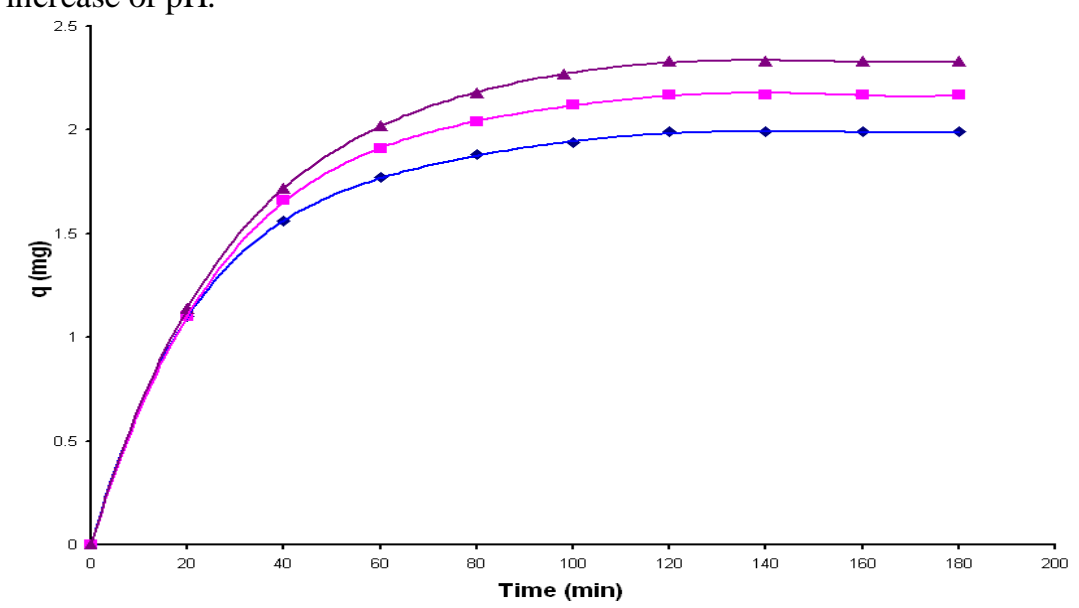

Fig 7: Effect of $\mathrm{pH}$ on the sorption of $\mathrm{Cu}(\mathrm{II})$ on chitosan; $\bullet 2.0, \cdot 4.0, \quad 6.5$; temp: $30^{\circ} \mathrm{c}$, conc. $100 \mathrm{mg} / \mathrm{l}$.

\begin{tabular}{|c|c|c|c|}
\hline Temperature $\left({ }^{\circ} \mathrm{C}\right)$ & $\Delta \mathrm{G}^{0}\left(\mathrm{kcal} . \mathrm{mol}^{-1}\right)$ & $\Delta \mathrm{H}^{\circ}\left(\mathrm{kcal} \cdot \mathrm{mol}^{-1}\right)$ & $\Delta \mathrm{S}^{\circ}\left(\mathrm{kcal} \cdot \mathrm{mol}^{-1}\right)$ \\
\hline 30 & -5.29 & 15.18 & 23.41 \\
\hline 40 & -7.60 & 25.92 & 36.28 \\
\hline 50 & -9.68 & & \\
\hline
\end{tabular}

Table 2: Thermodynamic parameters at different temperatures

\section{Conclusion}

From the above discussion it is clear that due to chemical composition, structure, more adsorption sites, cheap, availability in plenty etc. this substance will provide to be efficient adsorbent. 


\section{Acknowledgement}

The authors are thankful to Dr. Nagesh Gaveli, Director, Sudarshan College of science, management \& research, Pune (Maharashtra), for providing research facilities, co- operation and constant encouragement to carry out the work.

\section{References:}

[1] Yadav, K.P., Tyagi, B.S.Pandey, K.K and. Singh., Flyash for the treatment of cd (II) rich effluents. Env. Tech. Letter, (8), 225234 (1989)

[2] Singh, V.N., Singh, I.S. and Singh, N.P., Removal of Cu (II) from aqueous solution by fly ash. Indian Journal of Technology, 22(2), 22-27 (1984)

[3] Vishwakarma, P.P. and Singh, V.N., Removal of Ni (II) by China Clay. Asian Environment, 11(3): 49-64 (1984)

[4] Pandey. K.K. Prasad, G. Singh, V.N., Fly ash China Clay for the removal of Cr (VI) from aqueous solution. Indian Journal of Chemistry, 23( A), 514-515 (1984)

[5] Namasivayam C., and Yamuna R T., Environ Pollut., 9 (1). 1 - 4 (1985)

[6] Sekeran G., Shanmugasundaram K A.., Mariappan M and Raghavan K V., Indian J Chemical Technol., 2, (311), $71-75$ (1995)

[7] Findon A., Mckay G., Blair HS., Transport studies for the sorption of copper ions by chitosan. J. Environ. Sci. Health, A2 8(1), 173-185 (1993)

[8] Gotoh T., Matsushima K., Kikuchi KI., Preparation of alginatechitosan hybrid gel beads and adsorption of divalent metal ions. Chemosphere, 5.5 (1), 135-140 (2004)

[9] Grosse DN., A review of alternative treatment process for metal bearing hazardous waste streams. J. Air Pollution Contr. Assor. 36, 603-614 (1986)

[10] Ikhuoria EU., Omonmhenle SI., Removal of heavy metals from aqueous solution by adsorption onto chemically modified pumpkin. (Telfaira accidentalis Hook) Seed Husk, J. Chem. Soc. Nig. 31(1\&2),109-113 (2006) 